\title{
KONSTRUKSI LATAR DALAM FIKSI ETNOGRAFIS ORANG-ORANG OETIMU
}

\author{
Maria Matildis Banda \\ Universitas Udayana \\ Posel: mbanda574@gmail.com \\ Artikel dikirim: 23 Juli 2021; Diterima: 21 Agustus 2021

\section{THE CONSTRUCTION OF SETTING IN ETNOGRAPHIC FICTION ORANG-ORANG OETIMU}

\begin{abstract}
This paper examines the setting construction in the ethnographic fiction of OrangOrang Oetimu by Felix K. Nesi. Analytical descriptive methods, oral tradition, narratology, and setting theory were used to answer questions about: colonial and decolonial settings, socioeducational, ethnographic, and military violence setting. The results depict that the colonial and decolonial grounds left scars on the nation, which experienced previous neglect and alienation in their land. This long-experienced trauma affects massive social, education, and military violence behaviors. In addition, colonial and decolonial history also intersects with ethnographic, mainly traditional beliefs about local history and myths about "sifon," which is a tradition of having sex after circumcision. Unpredictable and irreversible patterns of colonial, decolonial, and ethnographic settings are also shockingly strengthening the plot, proofing that the well-constructed set produces quality and innovative story, narrative, and narrating.
\end{abstract}

Keywords: ethnographic fiction, background construction, colonial, decolonial

\section{PENDAHULUAN}

Karya sastra dengan ciri etnografis pada umumnya ditulis dengan perencanaan tertentu. Latar dikonstruksi melalui studi kepustakaan dan pengamatan lapangan untuk mendapatkan data-etnografi yang diperlukan. Etnografi adalah tulisan tentang atau mengenai satu (atau beberapa) etnis, suku, atau bangsa (Sulasman, 2013:104). Sastra etnografis adalah karya sastra yang menarasikan etnis tertentu melalui karya sastra. Karya fiksi jenis ini mengandung kultur lokal dan karakter daerah tertentu yang khas; tercermin pada tema, gaya pengucapan, aspirasi, latar, dan karakter kedaerahan (Sehandi, 2017:4). Perencanaan mengkonstruksi latar mempengaruhi estetika struktur intrinsik karya sastra secara umum seperti rangkaian peristiwa, alur, tokoh, dan karakter tokoh-tokoh. Hal ini dapat dicermati antara lain dalam novel Lolong Anjing di Bulan (Nur, 2016) berlatar Daerah Operasi Militer (DOM) Aceh); Suara Samudra (Banda, 2017) tentang tragedi lamafa (penikam ikan paus) dalam tradisi penangkapan 


\section{STILISTIKA}

ikan paus di Lembata; Orang-Orang Oetimu (Nesi, 2019) dengan latar kolonisasi dekolonisasi, tradisi, sosial pendidikan, dan kekerasan sipil dan militer di daerah pulau Timor pada umumnya dan daerah Oetimu khususnya. Pada kesempatan ini dipilih Orang-Orang Oetimu karya Felix K. Nesi. Novel Orang-Orang Oetimu (selanjutnya disingkat OOO) ditulis dengan alur sorot balik. Bercerita tentang tokoh Siprianus Portakes Oetimu (Ipi/Sersan Ipi). Pada bagian pertama (1) Sersan Ipi menyiapkan jamuan untuk penonton final sepak bola dunia antara Brasil dan Perancis. Jamuan ini untuk merayakan hubungan cintanya dengan Silvi yang sudah diperistri; dan berakkhir dengan Sersan Ipi tewas terbunuh Atino akibat balas dendam pada bagian akhir (14). Pada bagian dua (2) sampai tiga belas (13), "pembaca diajak menelusuri latar belakang tiap tokohnya yang sebetulnya merupakan elaborasi dari adegan pada bab pertama dan terakhir." (Laksana, 2018). Elaborasi yang menjelaskan rangkaian peristiwa dan konflik tokoh-tokoh Laura (korban perang saudara dan perkosaan di Dili, ibunda Sersan Ipi), Am Siki (orang tua angkat Laura dan Ipi), Romo Yosef, Maria, Silvi, dan dukun sunat Naef Ahelef. Alur berada dalam latar kolonial dan dekolonisasi, sejarah lokal, kepercayaan tradisional, kemelaratan dan keterpinggirkan, kritik terhadap institusi agama, keamanan, dan negara, eksploitasi pemberontakan, kekerasan, kepiluan, rasa sakit, dilengkapi fantasi dan prilaku seksual, serta sopi (minuman keras).

Ada beberapa alasan mengapa novel ini dipilih sebagai fokus kajian. Pertama, dari aspek struktur cerita disajikan dengan intensif, padat dalam tempo cepat, dan menerebos tradisi. Maksudnya diksi yang digunakan tidak biasa bagi novel dengan latar daerah Timor lainnya seperti karya-karya Gerson Poyk, Fanny Poyk, Mezra Pelondow, Dicky Senda, Christian Senda, Maria M. Banda (Sehandi, 2017, 2021). Novel ini dapat dikatakan "gila" dalam peristiwa yang terjadi dan ungkapan-ungkapan yang terlontar seperti: makian, tragedi kematian yang begitu mudah, masturbasi dan hubungan seks, dukun sunat yang terbunuh, laki-laki turunan pohon lontar, dan berita tentang tragedi lahirnya pahlawan kusuma bangsa.

Kedua, salah satu ciri yang menonjol dalam novel ini adalah keberanian dan ketakberbebanan menyajikan peristiwa dan konflik dengan diksi yang lugas dan denotatif. Tampaknya ada kesamaan antara pengetahuan dan apa yang diungkapkan narator melalui tulisannya dengan keberanian dan tanggung jawabnya (Banda, 2016:575). Bahkan hal-hal yang tabu untuk dibicarakan secara terbuka dalam keluarga 


\section{STILISTIKA}

dan masyarakat pun disampaikan to the point dan jujur. Inilah salah satu keunggulan OOO dalam mengeksploitasi kekuatan kata dan bahasa.

Ketiga, sebagai pencerita Felix K. Nesi sudah dikenal antara lain melalui kumpulan cerpen Usaha Membunuh Sepi (2016). Orang-Orang Oetimu mendapat kehormatan sebagai pemenang pertama lomba penulisan novel dari 245 naskah yang dinilai. OOO adalah "contoh fiksi etnografis yang digarap dengan baik," (Laksana, 2018). Novel setebal 220 halaman dilengkapi dengan daftar istilah dan singkatan serta enam baris keterangan tentang siapa penulisnya, diterbitkan Margin Kiri, Tangerang Selatan (2019). Berkat karyanya ini Felix K. Nesi terpilih untuk mengikuti residensi penulis di Belanda dengan dukungan Komite Buku Nasional (2019).

Berdasarkan ketiga hal di atas, kajian ini akan menyoroti secara khusus tentang konstruksi latar dalam fiksi etnografis OOO. Latar yang dikonstruksi secara terencana diyakini menghasilkan karya sastra inovatif dari sisi isi cerita (story), penceritaan (narative), dan karya sastra itu sendiri (narrating). Kajian ini akan menyoroti apa saja latar yang dikonstruksi dalam $O O O$ sebagai fiksi etnografis? Tujuannya untuk menggarisbawahi bagaimana latar yang dikonstruksi secara komprehensif mempengaruhi intensifitas dan integritas tokoh, konflik, serta rangkaian peristiwa dalam novel.

Novel $O O O$ karya Felix K. Nesi ini sudah banyak dikaji antara lain kajian dekonstruksi, bentuk kekuasaan, dan hegemoni sebagai berikut. "Kajian Dekonstruksi Novel Orang-Orang Oetimu" (Idhia Pramesti, tth) mendeskripsikan unsur dekonstruksi dalam novel. "Bentuk Kekuasaan dalam Novel Orang-Orang Oetimu" (Nisak dkk., 2020) mendeskripsikan struktur sosial masyarakat Oetimu, bentuk hegemoni dan dominasi agama, negara, dan militer dari masyarakat sosial kelas atas terhadap kelompok sosial kelas bawah. "Hegemoni Kekuasaan dalam Novel Orang Orang Oetimu: Kajian Sosiologi Sastra" (Nurhidayah, 2020). Menjelaskan dua, bentuk hegemoni dalam $O O O$ yaitu dominasi dengan cara kekerasan serta hegemoni ideologi dengan cara yang halus melalui berbagai pemikiran untuk menghasut orang lain. "Hegemoni Negara dalam Novel Orang-Orang Oetimu (Kajian Hegemoni Antonio Gramsci) (Hildayati, 2020). Kajian ini menyimpulkan adanya bentuk hegemoni yang dilakukan oleh para penjajah dan negara.

Kajian lainnya terhadap OOO adalah "Pola Penceritaan Novel Orang-Orang Oetimu Karya Felix K. Nesi" (Firmansyah, dkk. Tth.). Sebuah kajian mendalam tentang OOO sebagai teks naratif dengan dua bagian utama yaitu rangkaian peristiwa (story) 


\section{STILISTIKA}

dengan muatan karakter beserta hal yang berhubungan dengan latar di dalamnya dan wacana (discourse), yaitu ekspresi sebagai sarana untuk mengomunikasikan isi cerita (Cahtman, 1980 melalui Firmansyah, dkk. 2020). Kajian ini menggunakan pendekatan narrative discourse menurut Gerard Genette (1980) yang menggunakan tiga kategori struktur naratif sebagai dasar pemikirannya yaitu tense, mood, dan voice. Genette kemudian membuat signifikansinya dengan merumuskan lima unsur dalam teks naratif sebagai berikut: urutan (order) yang mengacu pada hubungan antara urutan kejadian dalam cerita dan penyajian dan penceritaan; durasi (duration) yang melihat perbedaan antara waktu dalam cerita dan waktu dalam penceritaan; frekuensi (frequency) untuk menganalisis keseringan terjadinya peristiwa dan seberapa sering disebutkan dalam penceritaan; modus (mood) untuk mengetahui kedudukan atau posisi pengarang dalam cerita; dan tutur (voice) yang berhubungan dengan siapa yang bercerita dan dari mana ia bercerita (Genette, 1980:31; Firmansyah, 2020:589)

Firmansyah menggunakan konsep urutan naratif (order) dan durasi naratif (duration) dalam mengkaji pola penceritaan dalam OOO. Dua hal ini berhubungan dengan konstruksi latar dalam fiksi etnografi OOO. Pertama: memperhatikan urutan peristiwa pada bagian pertama dan bagian ke empat belas yang menentukan nasib tokoh utama Sersan Ipi; dan peristiwa sorot balik dalam bagian kedua sampai ketiga belas dengan berbagai konflik tokoh Sersan Ipi, Selvi, Am Siki, Romo Yosef, dan lainlain. Kedua: memperhatikan waktu cerita (Lisabon 1974, Kupang 1995, dan Oetimu 1998); dan waktu penceritaan yaitu ketika OOO diceritakan dan menjadi sebuah cerita (novel).

Selain kajian yang dilakukan Firmansyah ditemukan pula kajian tentang "Kejadian Tidak Biasa dalam Novel Orang-Orang Oetimu karya Felix K. Nesi" (Ungkang, 2019) dengan konsep naratologi yang dielaborasi oleh Wolf Schmid (2010). Ungkang menjelaskan bahwa lima fitur penciri kejadian tidak biasa menurut Schmid adalah sesuatu yang gradasional. Salah satunya yang dijelaskan Ungkang lebih jauh adalah 'hal yang tidak dapat disemulakan lagi (irreversibility)'. Semakin kecil peluang suatu perubahan dikembalikan ke posisi awalnya semakin tinggi tingkat ketidakbiasaannya. Sejumlah kematian para tokoh dalam Orang Orang Oetimu adalah peristiwa yang tidak dapat dikembalikan ke keadaan sebelumnya (Ungkang, 2019). Felix K. Nesi melalui OOO mengemukakan kekayaan tradisi lisan baik tradisi lisan murni seperti bahasa rakyat (folkspeech), tradisi lisan sebagian lisan seperti 


\section{STILISTIKA}

kepercayaan tradisional, maupun tradisi lisan bukan lisan seperti obat-obatan tradisional (Danandjaya, 1984; Emzir, 2015:229).

Berdasarkan sejumlah penelitian tersebut di atas, diketahui bahwa kajian tentang konstruksi latar dalam fiksi etnografi Orang-Orang Oetimu belum pernah dilakukan. Kajian ini akan menggunakan teori naratologi menurut Genette, teori tradisi lisan menurut Danandjaya, serta teori latar yang sering digunakan dalam penelitian struktur sastra (Kosasih, 2014). Menurut Kosasih (2014: 67), latar atau setting meliputi tempat, waktu dan budaya yang digunakan dalam suatu cerita. Latar berfungsi untuk memperkuat atau mempertegas keyakinan pembaca terhadap jalannya suatu cerita yang dikonstruksikan. Dikonstruksikan artinya karya fiksi itu dibangun dengan perencanaan yang baik sehingga tidak menekankan segi nonrealnya tetapi segi konstruksi, segi inventif, dan segi kreatifnya (Kleden, 1998:13-15; Banda, 2019:xxii).

Kajian ini menggunakan metode kualitatif deskriptif serta metode etnografi (Nazir. Moh. 2013). Metode kualitatif deskriptif dilakukan berdasarkan langkahlangkah menuju kritik sastra. Diawali dengan membaca apresiatif untuk mendapatkan kesan umum dan membaca kritis dengan mencatat hal-hal penting berkaitan dengan rangkaian peristiwa yang membentuk alur, konflik antara tokoh dan penokohan (karakter), latar cerita, serta aspek intrinsik lainnya. Pada tahap ini dilakukan pencatatan data-data novel sebagai data primer dalam bentuk kata-kata, frasa, dan kalimat yang berkaitan dengan konstruksi latar. Metode etnografi yang digunakan terutama untuk membaca kritis simbol-simbol budaya yang terdapat dalam novel dan mencari relasi antara simbol. Pada tahap ini dilakukan pencatatan data-data tradisi lisan lokal. Selain data primer yang diperoleh melalui teknik pencatatan secara kualitatif, kajian ini juga menggunakan sumber data sekunder berupa jurnal dan tulisan lainnya tentang $O O O$ yang telah disebutkan dalam kajian pustaka.

Instrumen yang digunakan dalam penelitian berupa tabel data-data yang telah dikumpulkan untuk dikaji lebih lanjut. Langkah-langkah kajian yang dilakukan: 1) membaca kritis novel $O O O$ untuk mendapatkan data yang diperlukan dalam kajian; 2) kajian data berdasarkan teori wacana naratif Genette, teori tradisi lisan Danandjaya, dan teori latar Kosasih. 


\section{HASIL DAN PEMBAHASAN}

\section{Konstruksi Latar dalam Fiksi Etnografis Orang-Orang Oetimu}

Konstruksi latar menggarisbawahi sebuah upaya mempersiapkan latar secara terstruktur, untuk menempatkan latar yang dipelajari, digali, disiapkan melalui penelitian kepustakaan maupun lapangan. Pengarang memiliki pengetahuan tentang sejarah Timor Leste dan pengetahuan etnografi tentang Timor secara keseluruhan. Pengetahuan ini menjadi latar penulisan novel $O O O$ yang dikaji pada kesempatan ini: latar kolonialisasi dan dekolonisasi; latar sosial pendidikan dan kekerasan militer; dan latar etnografi.

\section{Latar Kolonialisasi dan Dekolonisasi}

Revolusi di Portugal berpengaruh langsung pada pergolakan politik di daerahdaerah koloni, termasuk di dalamnya Timor-Timur. Konflik dimulai di dan dari Lisabon, ibu kota Portugal. OOO membawa pikiran ke dalam kolonisasi yang terjadi di Timor bagian timur saat masih dalam status Provinsi Seberang Lautan di bawah kekuasaan Portugis serta sebelumnya dalam genggaman Belanda dan tarik-menarik kepentingan politik antara Belanda dan Portugal.

Gejolak politik di Lisabon berdampak pada gejolak politik di Provinsi Seberang Lautan (daerah-daerah jajahan Portugis) termasuk Timor Timur. Julio Craveiro dos Santos dikirim ke Timor untuk mendampingi Mario Lemos Pires dalam proses dekolonisasi. Tujuannya agar proses ini dapat berlangsung dengan tertib, lancar, dan terbaik bagi Portugal sebagai penjajah dan Timor Timur sebagai daerah kekuasaan (jajahan). Julio datang bersama istrinya Helena dan putri tunggalnya Laura. Kronologis cerita mulai 1974 dimana nasib keluarga kecil asal Portugis ini pun ditentukan oleh konflik dalam ketegangan tinggi antarpartai di tengah arena kolonisasi menuju dekolonisasi dimana campur tangan Indonesia memperparah nasib Julio dan keluarganya.

Ada tiga partai yang berdiri menjelang dekolonisasi itu. UDT yang menginginkan persatuan dengan Portugal, Fretelin yang menginginkan kemerdekaan penuh, dan Apoditi yang kecil yang ingin bersatu dengan Indonesia, negara tetangga bekas jajahan Belanda (OOO, hlm.14).

Proses dekolonisasi gagal total akibat tidak adanya kata sepakat dari ketiga partai untuk mengambil alih tampuk kekuasaan dari Portugis dan menjadi negara 


\section{STILISTIKA}

merdeka tanpa campur tangan bangsa lain. UDT dan Apoditi bergabung dan ingin bergabung menjadi bagian dari Indonesia, sementara Fretelin ingin berdiri sendiri sebagai sebuah negara baru. Portugis yang sudah sadar untuk mencabut kuku penjajahannya di Timor ternyata tidak dapat berbuat banyak ketika kelompok politik terpecah. Dekolonisasi pun berubah menjadi kolonisasi baru dimana Indonesia menjadi kuku penjajahan baru menggantikan Portugis. Perang saudara terjadi. Siapa pun yang mendukung Fretelin dicurigai, dituduh komunis, ditangkap, dan dibunuh.

Partai UDT baru saja amelancarkan kudeta, menduduki kota dan pusat-pusat pemerintahan termasuk kantor polisi. Julio dan Kapten Gustavo dibawa ke kantor polisi...dimasukkan ke sel dan diperlakukan seperti tahanan, disebut komunis dan ditanyai tentang rencana fretelin dan hal-hal lain yang sama sekali tidak Julio pahami... (OOO hlm.18-19). Sementara ia merasa ditinggalkan oleh negaranya, orang-orang fretelin selalu menyambutnya dengan hangat dan memuji aksinya.... Lama kelamaan Julio merasa memiliki sebuah negeri baru yang mencintainya.... Maka mulailah ia bekerja bersama fretelin. Ia ikut memperjelas arah perjuangan, menyingkirkan orang-orang yang tidak setia, dan mendeklarasikan kemerdekaan (OOO, hlm.21).

Julio terjebak dalam masalah besar karena dianggap berpihak pada Fretelin yang dituduh komunis. Masuknya Indonesia ke wilayah itu sebagai bentuk kolonialisasi baru yang lebih memecah belah, dimana kepentingan politik memicu perang saudara. Banyak orang ditangkap, termasuk Julio, Helena istrinya, dan Laura putri tunggalnya. Julio dan Helena ditembak mati di dermaga sementara Laura dibawa oleh tentara dan sejak itulah penderitaan Laura dimulai.

Usai eksekusi itu sebuah mobil membawa Laura dan perempuan-perempuan muda leinnya ke Hotel Tropical di Lecidere, jauh ke sebelah timur. Disitulah penderitaannya dimulai. Ia diperkosa, diinterogasi, dan disiksa. Berbulan-bulan di tempat itu, Laura dipindahkan ke gedung bekas toko Sang Tai Hoo di Colmera. ...mendapat perlakuan yang ia terima tidak pernah berubah. Kadang seseorang masuk dan memperkosanya. Kadang ia diangkut dengan jip ke mes seseorang yang akan menyetubuhinya (OOO hlm. 25). Pada suatu malam seorang laki-laki timor mendatanginya. Ia pikir ia akan diperkosa, tetapi laki-laki itu membawanya keluar. "Saya bertugas membunuhmu," katanya dalam bahasa Portugis, "tetapi saya telah melihat terlalu banyak kematian. Keluar dan bunuhlah dirimu sendiri sebelum saya berubah pikiran." (000 hlm. 26). Dia berjalan sangat jauh...seperti orang kehilangan pikiran ... perutnya semakin 


\section{STILISTIKA}

membesar. Rambutnya kaku dan berbau dan ia menjadi sangat buruk rupa. Ia terus menyusuri sungai ke arah barat ia berjalan $(O O O, \mathrm{hlm} .27)$

Perebutan kekuasaan, kolonisasi, dekolonikasi telah menghancurkan hidup sebuah keluarga dan penderitaan berkepanjangan yang dialami Laura sesungguhnya adalah penderitaaan lahir batin yang mesti dialami oleh rakyat yang tidak mengerti apa sesungguhnya terjadi dan ke arah mana mereka dibawa. Laura adalah simbol penderitaan yang dibangun kolonialisasi.

Substansinya sama dengan penderitaan tokoh-tokoh Saksi Mata yang diadili dalam keadaan tanpa mata dalam Saksi Mata (Seno Gumira Ajidarma), Isabela yang menderita dan terperangkap dalam masa lalu dilumuri darah dan kepahitan hidup dalam Surat-Surat dari Dili (Banda, 2005), serta pilihan politik yang menghancurkan hubungan saudara sekandung, Inan, dan Susana dalam Doben (Banda, 2000 dan 2017) serta beberapa kisah lain tentang Timor Timur sebelum menjadi Timur Leste. Dalam OOO latar kolonial dan dekolonial tampak selalu memikiki relasi timbal balik dalam kekerasan sosial pendidikan dan kekerasan militer berikut ini.

\section{Latar Kekerasan Sosial Pendidikan dan Kekerasan Militer}

Penanda urutan naratif (order) dan durasi (duration) sebagaimana dijelaskan Firmansyah (2020) serta tempat, Kupang 1995, disampaikan dengan jelas saat mengkonstruksi latar kekerasan sosial pendidikan serta kekerasan Militer. Konstruksi ini diungkapkan dengan syarat kritik diawali dengan dipindahkannya Romo Yosef dari kota untuk bertugas di Teluk Kupang dan menjalankan tugas baru sebagai kepala sekolah SMA Santa Helena. Pada awalnya sekolah ini melayani anak-anak nelayan, pekerja dengan kehidupan sosial ekonomi lemah. Karena kekacauan politik yang terjadi di Timor-Timor terutama pilihan politik yang memecah belah, ribuan orang dari Timor-Timur mengungsi ke Timor barat (NTT). Sekolah ini terlantar dan diselematkan Romo Yosef.

SMA Santa Helena telah menunjukkan eksistensinya di bawah pimpinan Romo Yosef. Bidang akademis dan ekstrakurikuler yang menjadi ciri sekolah itu terpublikasi secara luas. Sementara itu tanpa disadari sekolah menjadi eksklusif dan di luar jangkauan masyarakat pinggiran dengan ekonomi di bawah rata-rata.

Biayanya telah menjadi lebih mahal empat kali lipat. Jika pun bisa mendapatkan bea siswa yang ditawarkan. Kewajiban untuk tinggal di asrama membuat 
mereka berpikir dua puluh dua kali untuk bertahan. Sebagai anak orang miskin mereka tidak bisa tinggal di sekolah bahkan hanya untuk setengah hari. Sesudah jam sekolah berakhir, ada sangat banyak pekerjaan yang menanti mereka di rumah.... Meski pereka tahu tidak akan jauh kemana garis hidupnya. Anak nelayan akan mati sebagai nelayan, anak kuli akan mengganti bapaknya, dan anak pelacur akan ditiduri oeh pelanggan ibunya (OOO, hlm. 99-100).

Kutipan di atas ini mengkritisi persoalan pendidikan yang ada di tengah masyarakat. Sekolah favorit dengan berbagai fasilitas hanya memberi kesempatan bagi anak-anak dengan dukungan finansial yang optimal dari orang tuanya. Dalam latar inilah karakter tokoh dan konflik antartokoh menggerakkan cerita melalui banyak peristiwa. Beberapa di antaranya dijelaskan berikut ini.

Kepindahan RomoYosef dipicu oleh hubungan asmaranya dengan Maria. Maria adalah sahabat diskusi saat Yosef masih berstatus frater, sebelum ditahbiskan sebagai imam, dan berlanjut sampai menjadi imam. Maria yang frustrasi karena malu perselingkuhannya dengan Romo Yosef diketahui Romo Kepala. Dia juga malu pada almarhum suami dan anaknya yang meninggal akibat kecelakaan di jalan raya akibat kendaraan militer yang merajai jalanan dan menyebabkan Wildan dan Riko (suami dan anak Maria) tewas (OOO, hlm148).

Biasanya Wildam sendirian, tetapi itu adalah kali kedua ia membawa Riko. ... Mereka terseret sembilan meter dan kena gilas tiga truk lain... Tentara sedang terburu-buru karena perang. Seharusnya penduduk sipil minggir saat melihat unimog. Sesudah berhenti tidak begitu lama, iring-iringan itu berlalu. Sudah ada perwira yang digaji untuk memberikan pidato belasungkawa di pemakaman warga sipil (OOO, hlm:149).

Kekerasan juga dialami oleh Silvi Hakuak Namepam (Silvi), siswi SMA Santa Helena. Silvi masuk sekolah dengan nilai terbaik dan mendapatkan bea siswa penuh dan buku rekening (OOO, hm.106). Dia mengalami pelecehan seksual dan tinggalkan sekolah itu setelah mengalami pemerkosaan yang dilakukan seorang guru.

Di Oetimu Silvi bertemu dengan Sersan Ipi. Sersan Ipi adalah anak yang lahir karena korban perang dan perkosaan yang dialami Laura. Masa akil baliknya mengalami kekerasan seksual dari dukun sunat. Dia tumbuh menjadi laki-kaki dengan watak keras dan menjadi lebih keras lagi setelah sebagai polisi. 


\section{STILISTIKA}

Ia bangun pagi-pagi sekali, mengenakan seragam lengkap, lalu pergi ke kota dan mengabarkan hal itu kepada teman-temannya. Atas dasar jiwa korsa mereka turun ke jalan dan menangkap setiap pengemudi yang tidak tertib. Mereka juga mendatangi setiap tokoh yang menjual minuman keras. Dari pengendara mereka mendapatkan banyak uang, dari pertokoan mereka menyita bermacam-macam minuman. Berbekal itu semua, Sersan Ipi pulang ke Oetimu dan mengadakan jamuan di malam final piala dunia (OOO, hlm. 207).

Perilaku Romo Yosef atas nama institusi pendidikan dan agama. Kekerasan yang dilakukan oknum-oknum tentara dan polisi yang mendominasi atas nama institusi. Dalam latar sosial kekerasan pendidikan dan kekerasan militer berbagai kontradiksi dilukiskan melalui konflik tajam tentang sekolah favorit, realitas sosial masyarakat kelas atas dan kelas bawah, peran pendidik, juga aspek eksploitasi seksual yang membuat 'telinga merah'.

\section{Konstruksi Latar Etnografi}

Fiksi etnografi berkaitan dengan karya fiksi dengan warna daerah atau warna lokal yang dihadirkan dalam kesadaran kritis maupun etis. Kesadaran kritis dalam mengungkap berbagai masalah lokal dan kesadaran estetis merangkaikannya dalam karya sastra (Banda, 2019:xxxviii). Pengarang pada umumnya menulis latar daerah yang dikenal dengan baik, mempelajarinya melalui studi kepustakaan, maupun melakukan observasi lapangan untuk mendapatkan berbagai informasi etnografi sebagai latar cerita. Dalam novel $O O O$ latar etnografi terintegrasi dengan latar kolonial dan dekolonial serta latar kekerasan sosial pendidikan dan kekerasan militer.

Konstruksi latar etnografi dieksplisitkan dalam cerita, khususnya mengenai karakter tertentu yang terselip dalam tradisi lisan mengenai Timor dengan berpedoman pada mitos-mitos yang dimiliki masyarakat pada daerah atau kawasan tertentu (Neonbasu, 2013:2). Pemahaman dalam rangka budaya ini dimaksudkan sebagai upaya memahami arah dan sumber-sumber gejala sosial budaya (Taum, 2018:92) yang terdapat dalam novel yang berhubungan dengan pandangan hidup orang Timor. Pandangan hidup ini tergambar dalam simbol-simbol bahasa rakyat, kepercayaan tradisional, sejarah lokal, hukum dan lingkungan alam, kesenian rakyat, dan lainnya.

Pada kesempatan ini akan dijelaskan kepercayaan tradisional yang terdapat dalam $O O O$ dimana tokoh-tokoh tertentu berperan di dalamnya. Oetimu adalah tempat Laura melahirkan putranya Siprianus Poltakes Oetimu (Ipi) yang kemudian menjadi 
Sersan Ipi; tokoh Am Siki yang merawat Laura dan memelihara Ipi; dukun sunat Naef Ahelet yang berpengaruh pada pembentukan karakter Ipi, kepercayaan tentang sunat, dan tradisi sifon (berhubungan sex setelah sunat).

\section{Peramu dan Tokoh Masyarakat Lokal}

Hidup sebagai peramu dilakukan Am Siki sebab tempat tinggal sebelumnya tidak bersahabat disebut afu $i$ nata'an atau rai nee makaaslmanas (Tetun) yang berarti tanahnya panas (Manehat, 2013) sehingga diperlukan sebuah tempat yang damai yang baginya bisa menetap untuk selamanya. Tanah yang panas itu adalah perang dan penjajahan hal yang menyebabkan Am Siki melarikan diri dengan cara menjadi peramu sampai pada suatu saat tiba di Oetimu.

Seturut cerita turun-temurun, selain orang Timor secara keseluruhan, dikenal juga cara dan pola hidup manusia Atoni Pah Meto. Orang mengenal mereka sebagai peramu, yang berarti suka berpindah-pindah tempat akibat peperangan atau bahaya penyakit, atau tersebar oleh keagamaan asli dan alam sekitar yang tidak bersahabat dengan umat manusia (Manehat, 2013:74). Demikianlah yang terjadi dengan Am Siki dalam novel ini berpindah-pindah karena perang dan perebutan kekuasaan antara Portugis dan Belanda serta selanjutnya antara Belanda dan Jepang. Dalam latar ini, tokoh Am Siki ditampilkan dalam $O O O$ sebagai peramu yang disegani karena keberaniannya menentang penjajah dan sebagai pahlawan yang dihormati oleh masyarakat Oetimu. Dia dikenal sebagai tokoh pemberani, sakti, dan disegani.

Tidak ada seorang pun di seluruh penjuru negeri itu yang tidak mengenal Am Siki. Am Siki adalah satu-satunya lelaki yang pernah membunuh lebih dari sepuluh orang Jepang, membakar habis satu kam kerja paksa, dan masih hidup sampai sekarang (OOO, hlm: 32). Am Siki adalah pemuda yang selalu ada di dalam cerita-cerita dongeng. Sebatang kara, kuat, gesit, dan pekerja keras. Ia bisa mengiris malai dari dua belas pohon lontar hanya dalam waktu dua linting tembakau. Ia bisa menunggang kuda di tengah malam buta. Ia tidak pernah mendapat sial sebab selalu disertai oleh leluhurnya (33).

Am Siki juga meyakini bahwa dirinya adalah keturunan pohon lontar. Keyakinan ini berdasarkan pada pengalaman perjalanan hidupnya turun-temurun. Dirinya yakin bahwa para leluhurnya meninggal di bawah pohon daun lontar sebagaimana dijelaskan berikut ini. 
Keluarganya percaya bahwa di suatu masa yang lampau, leluhurnya tercipta dari pohon lontar; dan seperti begitulah cara mati yang turun-temurun terjadi di dalam keluarganya. Ayahnya mati di naungan lontar, kakeknya mati di naungan lontar, buyutnya dan seterusnya. Sebab tercipta dari lontar, maka mati terhempas dari pohon lontar adalah jalan pulang yang mulia untuk bersatu dengan leluhurnya (OOO, hlm. 33).

Ia rebah ke tanah dengan mata berkunang-kunang. Antara sadar dan tidak sadar ia melihat pohon lontar itu merunduk, mengamati wajahnya, dan sesudah tergemap sebentar, pohon itu membacakan syair dalam uab meto $(O O O, \mathrm{hlm}$ 37). Usai mmbaca syair itu tiga kali, sambil merentang-rentangkan tangannya dengan dramatis, lontar itu meludahi lengan dan kedua mata Am Siki...tubuhnya lebih kuat daripada kuda. Mandor yang datang untuk mencambuknya, ia tampar berkali-kali sebelum ia angkat tinggi-tinggi dan ia pecahkan kepalanya di batu karang hitam. Malam itu ia mengamuk. Ia membunuh setiap tentara Jepang dan membakar habis kamp itu. Mayat tentara Jepang bergelimpangan, api menjilat-jilat dan para pekerja kabur berhamburan (OOO, hlm.38).

Dalam pengembaraannya yang cukup panjang -mulai pendudukan Jepang sampai sesudah kemerdekaan - Am Siki tiba di Oetimu. Di Oetimu Laura (korban perang saudara pada masa dekolonisasi dan kolonisasi) bertemu dengan Am Siki. Am Siki merawat Laura layaknya anaknya sendiri. Dari mamahan obat Am Siki merawat Laura. "Am Siki melumuri tubuhnya dengan mamahan obat. Mamahan obat membuat lukanya mengering dan makanan dengan ramuan obat itu memulihkan kesehatannya. Di hari keempat belas daging mulai tumbuh di antara tulang dan kulitnya. Lukanya telah berhenti bernanah (OOO, hlm. 47). Laura menjadi ibu yang sangat sehat demi melahirkan anak yang diberi nama Siprianus Portakes Oetimu (Ipi) oleh Am Siki. Empat hari setelah melahirkan Laura meninggal karena tidak mau makan sejak anaknya lahir.

\section{Sopi, Sunat, dan Sifon}

Siprianus Portakes Oetimu (Ipi) dibesarkan oleh Am Siki sejak ditinggalkan ibunya. Laki-laki ini digambarkan memiliki kepribadian yang selalu ingin tahu, tertutup, dan memiliki keberanian melakukan apa pun demi menyelamatkan dirinya. Masa kecil Ipi sebagai pemasak nira untuk dijadikan sopi (tuak, minuman keras) serta menjualnya dinarasikan pada bagian ke-11 novel OOO. 
...ia menyalahkan api di tungku saenhana. Tungku 'saenhana' itu terbikin dari tiga bongkah batu besar-besar yang cukup kuat untuk menyangga periuk tanah sebesar empat kali kepala kuda. Sesudah api menyalah dengan sempurna, Ipi menuangkan nira yang telah siap dimasak yang telah ia rendami dengan ramuan rempah dari hutan yang dikumpulkan Am Siki dengan doa dan mantra. Setelah menunggu barang setengah jam, terkantuk-kantuk di depan tunggu sambil menghafal perkalian, menjadi didihlah nira itu, meruahkan buih putih lengketlengket seperti bubur singkong (OOO, hlm165).

Setiap titik uap akan masuk ke dalam bambu panjang dan secara ajaib berubah menjadi cairan yang menetes di ujung bambu. Tetes-tetes itulah sopi yang akan ia jual di pasar-pasar pagi. Setelah memastikan bahwa sopi telah menetes dengan sempurna ke penampungnya, Ipi membawa kudanya ke sungai untuk mandi, sebab ia harus ke sekolah. Jika itu hari libur, ia menyusul Am Siki ke pohon lontar (OOO, hlm 166).

Am Siki membesarkan Ipi sesuai apa yang bisa dilakukannya menyadap nira, memasaknya menjadi sopi, dan menjualnya. Ipi memelihara kuda sebagaimana Am Siki juga memiliki kuda. Dalam pertumbuhannya dari anak-anak menjadi remaja dan dewasa Ipi memiliki masalah pemahaman alat reproduksi dengan dirinya sendiri. Pertama, ketika mandi di sungai bersama teman-temannya; kedua saat berhadapan dengan Naef Ahelet seorang tukang sunat; dan ketiga sifon (salah satu ritual sunat yaitu berhubungan seks untuk menyembuhkan luka sunat).

Namun begitu Ipi menarik turun celananya, dua anak itu ternganga. Mereka baru kelas enam, tetapi kemaluan Ipi telah sangat besar, dua kali lebih besar dari kemaluan mereka. "Wah, sepertinya itu penyakit," seorang dari mereka memberi kesimpulan. "Bukan," yang lain membantah, "Sepertinya cacat." (OOO, hlm. 167)

Peristiwa itu adalah lah awal ketakutan Ipi yang berlanjut dengan pertemuannya dengan Naef Ahelet, satu-satunya dukun sunat di seluruh perkampungan dekat sungai Noenifu. Dukun ini telah memotong kemaluan ratusan laki-laki Atoin Meto. Bahkan setiap laki-laki harus mengenal Naef Ahelef sebab dirinya bisa memberi informasi tentang dimana pasiennya bisa melakukan sifon (OOO, hlm. 168).

Sifon adalah tradisi suku Atoni Meto (Dawan) di daerah Nusa Tenggara Timur (NTT). Sunat dilakukan untuk lelaki setelah menginjak usia 18 tahun. Keunikan ritual 


\section{STILISTIKA}

khitanan Suku Atoni Pah Meto di Provinsi Nusa Tenggara Timur ini, terletak pada proses penyembuhan luka akibat pengkhitanan, yaitu dengan cara melakukan hubungan seksual dengan perempuan bukan istri atau anggota keluarga dekat, atau perempuan yang tidak akan dinikahi oleh lelaki pelaku ritual Sifon (Hidayat, 2016:1).

Ipi dan kawan-kawan menemui dukun sunat ini dengan tujuan mengetahui dengan pasti apa sebenarnya yang terjadi dengan kemaluan Ipi. Pertemuan tersebut menjadi tragedi bagi Ipi sebab dukun sunat itu justru melakukan pelecehan seksual. Peristiwa yang menyenangkan, memalukan, menakutkan, menghantui Ipi seumur hidupnya, terhina, sekaligus menimbulkan rasa dendam (OOO, hlm.169-171, 199). Ipi dengan diam-diam menghabisi hidup Naef Ahelef saat disarankan melakukan sunat agar bisa segera ber-sifon oleh Am Siki (OOO, hlm. 200-2001).

Sunat, sifon, dan berbagai mitos tentangnya mengubah perilaku tokoh secara radikal. Banyak hal yang tidak terduga (unpredictibility). Ketakterdugaan juga bisa diartikan sebagai penyimpangan dari "norma" atau kelaziman yang ada dalam dunia cerita (Ungkang, 2019). Hal ini terjawab dari perilaku dukun sunat kepada Ipi sekaligus juga perilaku Ipi pada dirinya sendiri. Selain tidak terduga, dalam $O O O$ ditemukan juga hal yang tidak dapat disemulakan lagi (irreversibility) yaitu sejumlah kematian termasuk di dalamnya kematian si dukun sunat, Naef Ahelef.

Pemahaman dan perilaku seksual dan kekerasan seksual mengambil porsi yang cukup intens dalam OOO. Disampaikan secara terbuka oleh pencerita -sudut pandang orang ketiga- langsung, fulgar, tanpa rasa malu, membongkar tabu. Akan tetapi mengubah nasih tokoh sebagaimana dialami Laura, Naef Ahelef, Romo Yosef, Maria, Ipi, dan Selvi. Pertemuan Ipi dan Silvi terjadi karena upaya Ipi dalam kedudukannya sebagai Sersan Ipi, dalam pertemuan pertama sekaligus persetubuhan pertama. Ipi mematahkan mitos bahwa hanya lelaki bersunat yang bisa melakukan sifon. Dalam konteks ini pula $O O O$ memasuki bagian pertama (1) dan bagian akhir (14) cerita. Sersan Ipi tewas akibat balas dendam yang mengakar dalam masyarakat dengan mental terjajah. Kisah berakhir dengan ironi, "Sersan Ipi gugur dalam tugas kepahlawanannya untuk melindungi rakyat kecil. Sungguh, ia adalah seorang kesuma bangsa" (OOO, hlm.220).

\section{SIMPULAN}

Artikel ini menyimpulkan bahwa latar yang dikonstruksi secara terencana menghasilkan karya sastra yang berkualitas. Latar kolonial dan dekolonial Portugis 
yang menimbulkan perang saudara di Timor Timur baik saat dilepas Portugis (1974 1975) dan menjadi Propinsi ke-27 RI, maupun menjelang dilepas Indonesia (1998). Latar ini memberi pengaruh langsung pada latar kekerasan sosial pendidikan dan kekerasan militer yang terjadi secara masif dalam OOO. Dalam latar ini oknum-oknum yang seharusnya menjadi penyelamat dalam institusi agama (gereja), pendidikan, dan militer mendominasi terjadinya penderitaan berkepanjangan para tokoh. Berbagai bentuk pelecehan seksual diungkapkan secara jujur dan terbuka. Kedua latar ini beririsan dengan latar yang yang ketiga yaitu latar etnografi.

Dalam latar etnografi, kepercayaan tradisional tentang sejarah lokal lahirnya tokoh pahlawan (Am Siki), tradisi peramu, serta mitos-mitos tentang sifon dilukiskan. Sunat, sifon, dan berbagai mitos tentangnya mengubah perilaku tokoh secara radikal. Banyak hal yang tidak terduga (unpredictibility) dan hal yang tidak dapat disemulakan lagi (irreversibility) yaitu sejumlah kematian termasuk di dalamnya kematian si dukun sunat, Naef Ahelef, Laura, Maria, dan Sersan Ipi sendiri sebagai tokoh utama. Artikel ini perlu dikaji lebih jauh terutama tentang: simbol-simbol bahasa, sastra etnografi, dan proses kreatif pengarangnya.

\section{DAFTAR PUSTAKA}

Banda, Maria Matildis. 2019. Narasi Rindu, Tema Dan Kekuatan Konflik Dalam Merangkai Alur Cerita Antologi Cerpen Pesan Perdamaian Dari Bumi Flobamora . hlm. xiii-xl. Jakarta: Kosa Kata Kita.

Banda Maria Matildis. 2016. "Parrhesia dan Kekuasaan Sastrawan dalam Mengungkapkan Kebenaran" dalam Sudibyo dan Ilmu (ed). Isu-Isu Mutakhir dalam Kajian Bahasa dan Sastra. Hlm. 564-582. Yogyakarta: Interlude.

Bataona, Yosef Demon. 2021. "Harmoni Relasi Vertikal-Horisontal dalam Novel Suara Samudra Maria Matildis Banda" dalam Sehandi (ed). Antologi Esai dan Kritik Sastra NTT. Hlm. 383-390. Jakarta: Kosa Kata Kita.

Emzir, dkk.2015. Teori dan Pengajaran Sastra. Jakarta: Raja Prafindo Persada.

Firmansyah, dkk. 2020. Pola Penceritaan Novel Orang-Orang Oetimu Karya Felix K. Nesi Prosiding Seminar Internasional Riksa Bahasa XIV. Jakarta: UPI.

Genette, G. (1980). Narrative Discourse: An Essay in Method. Terjemahan oleh Jane E. Lewin. New York: Cornell University Press. 
Hildayati, N. F. \& Rengganis, R. (2020). Hegemoni Negara dalam Novel Orang-Orang Oetimu Karya Felix K. Nesi (Kajian Hegemoni Antonio Gramsci). Bapala, Volume 7, Issues 4 .

Kleden, Ignas. 1998. Fakta dan Fiksi tentang Fakta dan Fiksi: Imajinasi dalam Sastra dan Ilmu Sosial", dalam Kalam, Edisi II. Jakarta: Institut Studi Arus Informasi.

Kosasih, E. 2014. Dasar-Dasar Ketrampilan Bersastra. Bandung: Yrama Widya.

Laksana, A.S., dkk. (2018). Pertanggungjawaban Dewan Juri Sayembara Menulis Novel DKJ Jakarta 2018. https://dkj.or.id/artikel/pertanggungjawabandewan-juri-sayembaramenulis-novel-dewan-kesenian-jakarta-2018/diunggah 02 Juli 2021.

Nazir, Moh. 2013. Metode Penelitian. Ciawi Bogor: Ghalia Indonesia.

Nesi, Felix. K. 2019. Orang Orang Oetimu. Tangerang: Margin Kiri.

Nisak, Khoirun. Dkk. 2000. Bentuk Kekuasaan dalam Novel Orang-Orang Oetimu karya Felix. K. Nesi" dalam Bahtera Jurnal Pendidikan, Bahasa, dan Sastra, dan Budaya. Jilid 07 Nomor 2. Malang: UMM.

Nurhidayah, Dwi Ihsanu. 2019. Hegemoni Kekuasaan dalam Novel Orang Orang Oetimu: Kajian Sosiolog Sastra" dalam Prosiding Seminar Nasional Bahasa dan Sastra Indonesia.

Pramesti, Idhia. Tth. Kajian Dekonstruksi Novel Orang-Orang Oetimu. Jakarta: UM. Hamka.

Sehandi, Yohannes. 2017. Sastra Indonesia di NTT dalam Kritik dan Esay. Yogyakarta: Ombak.Ungkang, Marselus. 2019. "Kejadian Tidak Biasa dalam Novel Orang-Orang Oetimu Karya Felix K. Nesi dalam Baca Petra https://www.bacapetra.co diunggah Kamis, 08 Juli 2021.

\section{PROFIL PENULIS}

Maria Matildis Banda adalah alumni dan dosen Prodi Sastra Indonesia, Fakultas Ilmu Budaya, Universitas Udayana Denpasar Bali (1986 sampai sekarang). Aktif dalam penelitian dan seminar bidang bahasa, sastra, dan kebudayaan. Menulis karya kreatif yang berkaitan dengan bidang kesehatan seperti Rabies (2005), Wijaya Kusuma dari Kamar Nomor Tiga (2015), Suara Samudra (2017), Doben (2017). Dua novel baru Bulan Patah dan Pasola akan diterbitkan. Kolumnis tetap ruang Parodi Situasi Minggu Harian Umum Pos Kupang (2001 sampai sekarang). Maria sudah menulis 1000 episode parodi situasi (sekitar 2000 halaman) tentang isu pendidikan, kesehatan, ekonomi, politik, dan isu sosial budaya lainnya. 